http://dx.doi.org/10.21611/qirt.1994.027

\title{
Study of heat transfer enhancement on surface protuberances using infrared technique
}

\author{
by R. C. HENRY (*), R. J. HANSMAN (**) and D.L. BALAGEAS (*)
}

(*) ONERAL3C, BP 72, 92322 Chátillon cedex, France

(*) Massachusetts Institute of Technology, Cambridge MA 02139, USA

\begin{abstract}
In order to determine the effect of ice protuberances on local convective heat transfer coefficient, enhancement of heat transfer coefficient on small $(2 \mathrm{~mm}$ to $6 \mathrm{~mm}$ diameter) hemispherical elements on a flat plate has been studied in a wind tunnel using an infrared camera. The influence of size and density of protuberances and velocity are investigated for laminar and turbulent boundary layers on the flat plate. Maximum heat transfer is observed on the upstream face of protuberances and values increase strongly with roughness size and velocity for laminar conditions on the flat plate. For turbulent conditions, heat transfer enhancement is relatively constant with velocity, but increases with the size of protuberances. Results are also given for multiple elements configurations.
\end{abstract}

\section{Introduction}

Understanding the local convective heat transfer on rough ice surfaces is central to successfully modeling aircraft ice accretion because the accretion is controlled by the rate at which latent heat can be convected away from the icing surface [1]. Recent close-up video studies have observed ice growth from upstream face of surface protuberances [2]. This process is thought to be initiated by local enhancement in heat transfer which occurs on surface roughness which are approximately one $\mathrm{mm}$ in diameter.

Most prior studies of forced convective heat transfer from roughened surfaces focused on cases where the roughness height was small compared to the boundary layer thickness and most of traditional experimental methuds have investigated the averaged heat transfer over many roughness elements $[3,4]$. Consequently, it was necessary to develop an experimental technique to study local variation of heat transfer at high spatial resolution. Because infrared thermography was used successfully for heat transfer measurement in wind tunnel in the past $[5,6]$, this technique was employed for this study.

\section{Experimental set-up}

The experimental approach is based on thermographic measurements of the local perturbations in heat transfer caused by protuberances on a: uniformly heated surface. Measurements wero performed in a low turbulence (less than $0.2 \%),(30.5 \mathrm{~cm} \times 30.5 \mathrm{~cm}$ ) wind tunnel using the experimental set-up shown in figure 1. The test protuberances were mounted on a $50 \mathrm{~cm}$ long, 30 $\mathrm{cm}$ wide flat Plexiglass plate and were observed with an infrared camera.

Test protuberances typically consisted of plastic hemispherical beads. The test location was in the center of the plate, $25 \mathrm{~cm}$ downstream from the leading edge. The plate had a beveled leading edge with a $1.5 \mathrm{~mm}$ nose radius. For turbulent boundary layer tests, a $0.5 \mathrm{~mm}$ diameter wire was placed at the leading edge of the plate to trip the boundary layer. The turbulent boundary layer was verified by a drop in plate surface temperature (typically greater than $10^{\circ} \mathrm{C}$ ) which was observed by infrared imaging with the trip wire present. Thermocouples were included in the experimental sot= up to provide freestream air temperature data and reference surface temperature readings.

The test surface was heated with three $250 \mathrm{~W}$ infrared lamps to provide uniform heating in the roughness element area. Uniformity of heating was verified by measuring surface temperaturo

The colour plates of this article are on page $X I$ at the end of the book. 
without external flow. The plate and roughness elements were painted flat black to aid in uniform heating and to avoid false infrared temperature signals due to heat reflection.

A Hughes Probeye thermal video system was used to map surface temperatures. The infrared camera was located $15 \mathrm{~cm}$ above the plate and was focused on the roughness element zone through a hole in the upper wall of the test section. This system uses 6 short wavelength detectors $(2-5.6 \mu \mathrm{m})$ and 10 mirrors delivering 20 frames per second, each frame containing 60 lines. Spatial resolution was approximately $0.5 \mathrm{~mm}$ and temperature resolution was approximately $0.5^{\circ} \mathrm{C}$. The system displayed a color video image with temperature scales and temperature plots on selected cross sections. Temperature range and sensitivity could be adjusted and surface emissivity could be compensated, but due to the flat black surface, emissivity was assumed to be equal to unity. $A$ high temperature sensitivity approximately $0.5^{\circ} \mathrm{C}$ was generally used. The infrared images were recorded on a VCR for subsequent analysis.

\section{Heat transfer enhancement calculation}

In steady state, $Q_{\text {in }}$ coming from external heating and entering the protuberance is balanced by the sum of heat losses composed of forced convective flux $Q_{\text {conv, }}$, conductive flux into the plate $Q_{\text {cond }}$ and radiative flux $Q_{\text {rad }}$ :

$$
Q_{\text {in }}=Q_{\text {conv }}+Q_{\text {cond }}+Q_{\text {rad }}
$$

The heat conduction losses $Q_{\text {cond }}$ can be assumed to be small in steady state due to low conductivity materials (plexiglass and plastic). Radiative losses are typically less than $1 \%$ of convective losses for room temperature wind tunnel experiments and can also be neglected. Therefore, the primary heat sink for the surface is the convective flux which can be written as:

$$
Q_{\text {conv }}=h\left(T_{\text {sur }}-T_{\text {rec }}\right)
$$

Where $h$ is the convective heat transfer coefficient, $T_{\text {sur }}$ is surface temperature and $T_{\text {rec }}$ is the recovery temperature.

Since $Q_{\text {conv }} \approx Q_{\text {in }}$ and, assuming that the recovery temperature is close to the freestream temperature $T_{0}$, due to the low speed, the convective heat transfer coefficient can be written as

$$
h=\frac{Q_{\text {in }}}{\left(T_{\text {sur }}-T_{0}\right)}
$$

If the heating is relatively uniform (i.e., $Q_{\text {in }}$ is constant), the convective heat transfer coefficient in the area perturbed by the roughness elements, $h_{p}$, normalized by convective heat transfer coefficient in the unperturbed area $h_{u}$, (i.e. in the smooth area upstream the element) can be related to the surface temperatures in the perturbed and unperturbed regions.

$$
\frac{h_{p}}{h_{u}}=\frac{\left(T_{\text {suru }_{u}}-T_{0}\right)}{\left(T_{\text {surp }_{p}}-T_{0}\right)}
$$

The surface temperatures are measured with the infrared camera and the freestream temperature is measured by thermocouples.

Concerning the relative heat transfer coefficient accuracy, for low speed tests $(5 \mathrm{~m} / \mathrm{s})$, typical values of $\left(T_{\text {sur }}-\mathrm{T}_{0}\right)$ were on the order of $15^{\circ} \mathrm{C}$ in the unperturbed region and $10^{\circ} \mathrm{C}$ in the perturbed region. Assuming uncertainty in surface temperature measurement of $0.5^{\circ} \mathrm{C}$, this would correspond to an uncertainty of heat transfer coefficient ratio of approximately $8 \%$. For high speed tests (31 $\mathrm{m} / \mathrm{s}),\left(T_{\text {sur }}-\mathrm{T}_{0}\right)$ values were typically $10^{\circ} \mathrm{C}$ in the unperturbed region and $\left(5^{\circ} \mathrm{C}\right)$ in the perturbed region, corresponding to an uncertainty of $15 \%$. 


\section{Test procedure}

Tests were performed for freestream velocities varying from $5 \mathrm{~m} / \mathrm{s}$ to $31 \mathrm{~m} / \mathrm{s}$, resulting in local Reynolds numbers from 100,000 to 500,000 at test location $25 \mathrm{~cm}$ downstream from the leading edge. For each test, infrared thermographs of the protuberances region were recorded and the relative heat transfer coefficient was calculated versus position in the flow direction.

Two series of tests were performed with laminar and/or turbulent boundary layers. The first investigated the effect of protuberance size for single elements and the second one investigated the effect of interaction between multiple protuberances.

\section{Experimental results}

\subsection{Individual protuberances}

In order to investigate heat transfer on individual protuberances, the configuration shown in figure 2 was tested. The configuration consisted of four spherical roughness elements with heights varying from $0.75 \mathrm{~mm}$ to $2.8 \mathrm{~mm}$. The elements were slightly shorter than full hemispheres. Consequently the base radii were slightly larger than the heights. The center of each element was located $25 \mathrm{~cm}$ downstream from the plate leading edge and the cross stream separation between each element was approximately $3 \mathrm{~mm}$. This configuration was tested with both laminar and turbulent boundary layers.

\subsubsection{Laminar Boundary Layer Results}

A typical infrared thermograph of three protuberances $(2.8 \mathrm{~mm}, 0.7 \mathrm{~mm}$ and $1.7 \mathrm{~mm}$ high) at a freestream velocity of $22 \mathrm{~m} / \mathrm{s}$ is shown in color figure $A$. The flow is from the right and blue color indicates colder temperatures in the thermographic image. Significant variation in surface temperature and hence, heat transfer, can be seen on each protuberance with the coldest regions (i.e., highest heat transfer) on the upstream side of the elements. A second cold region is also observed in the boundary layer transition wedge downstream of the protuberance. The $2.8 \mathrm{~mm}$ and $1.7 \mathrm{~mm}$ high elements are seen to be significantly colder than the $0.7 \mathrm{~mm}$ high element.

The heat transfer enhancement profiles for the $2.8 \mathrm{~mm}$ high protuberance are plotted in figure 3 for several velocities. The profiles are taken through the middle of the element and downstream distance normalized by the radius of the bead $(3 \mathrm{~mm})$. The general shape of the curves are the same for each velocity. The heat transfer begins to increase at a distance of approximately 2 radii upstream of the elements. A peak in heat transfer is observed on the upstream face at about 1/2 radius downstream the leading edge of the bead. Then, the heat transfer coefficient decreases sharply to the downstream edge of the element. The heat transfer enhancement in the wake is typically $50 \%$ of the maximum value. Similar profiles were found for other protuberances.

The peak of heat transfer value, corresponding to the coldest region was found to be located approximately $1 / 2$ radius downstream the leading edge of the bead. This maximum heat transfer coefficient enhancement is plotted in figure 4 as a function of the local Reynolds number for the different roughness elements tested.

For the small roughness elements, the heat transfer enhancement is observed to be small and weakly dependent on Reynolds number in the range tested. For the larger elements, the enhancement is larger and is seen to increase with Reynolds number until a maximum at $R e=300$, 000. Above this value the boundary layer is assumed to have transitioned to turbulent which increases the heat transfer in the unperturbed region.

\subsubsection{Turbulent Boundary Layer Results}

A typical infrared thermograph for a turbulent boundary layer case at a freestream velocity of 18 $\mathrm{m} / \mathrm{s}$ is shown in color figure $B$. The temperature is similar on each element, indicating that the heat transfer enhancement is less dependent on protuberance size than for the laminar case. In addition, 
http://dx.doi.org/10.21611/qirt.1994.027

the enhanced heat transfer in the wake only persists a limited distance downstream of the protuberances, unlike the transition wedges observed in laminar cases.

The heat transfer enhancement profiles observed for the $2.8 \mathrm{~mm}$ high protuberance in a turbulent boundary layer are shown in figure 5 . The observed heat transfer enhancement profiles for the turbulent boundary layer are quite similar to those observed with a laminar boundary layer. However, the magnitude of the heat transfer enhancement is reduced due to the higher heat transfer in the unperturbed reference region. The ratio of heat transfer coefficient is seen to begin increasing approximately one diameter upstream of the element until it reaches a peak value of approximately 2.5. It then decreases to a minimum value at the downstream edge of the element.

The maximum heat transfer enhancements observed for the turbulent boundary layer cases are shown in figure 6 as a function of the local Reynolds number. The maximum heat transfer value extends from 1.5 for the small elements to 2.5 for the $2.8 \mathrm{~mm}$ tall roughness. The variation with Reynolds number is observed to be relatively weak. It should be noted that, because unperturbed heat transfer coefficients are high, the maximum heat transfer coefficients are actually higher than for laminar boundary layer cases.

\subsection{Multiple protuberances effects}

In order to study the influence of multiple roughness protuberances on heat transfer, configuration shown in figure 7 was tested under turbulent boundary layer conditions.It was constructed of $1 \mathrm{~mm}$ high, $2 \mathrm{~mm}$ diameter wax bead elements, spaced $2 \mathrm{~mm}$ apart in a rectangular grid.

The heat transfer coefficient profiles are plotted as a function of the distance from the center of the first protuberance in figure 8.The infrared thermographs were only sampled at the top of the elements and at one point within the gaps. The profiles are quite similar, with the exception of the lowest velocity tested $(9 \mathrm{~m} / \mathrm{s})$. The heat transfer coefficient enhancement is approximately 2 at the top of elements and 1.5 in the gaps. These values are approximately identical for all the protuberances.

\section{Conclusions}

Infrared technique has been used for high spatial scale measurement of heat transfer variation on individual protuberances. Measurements were made on hemispherical roughness elements on a flat plate. Significant enhancement in heat transfer was observed on the protuberances and in the wake when the elements protruded into the boundary layer. The highest heat transfer was observed on the upstream face of the elements.

- For laminar boundary layer conditions, the maximum heat transfer enhancement (referenced to the unperturbed flat plane) was observed to increase with roughness element size. Heat transfer enhancements as high as 8 were observed for $2.8 \mathrm{~mm}$ high protuberances. In addition, some enhancement in heat transfer was observed upstream of the element.

- For turbulent boundary layer conditions, the maximum heat transfer enhancement was not strongly dependent on velocity for the tested conditions. The peak heat transfer enhancements were observed to be between 2.1 ant 2.6 times the unperturbed turbulent heat transfer value for the flat plate.

- For multiple protuberances under turbulent boundary layer conditions, it was found that the heat transfer on each element was similar to that observed for the individual elements for $1 \mathrm{~mm}$ high protuberances, one diameter spaced.

- The enhanced heat transfer on the upwind face of the protuberance is consistent with the enhanced ice growth observed in previous studies. The observed enhancement of approximately 2.5 may be useful to predict the initiation of ice growth. The enhanced heat transfer observed upstream of the physical roughness element for the laminar boundary layer conditions may explain observed upstream propagation of the smooth-rough transition boundary observed for some glaze ice conditions. 
This work was supported by La Direction des Recherches, Etudes et Techniques, Le Service Technique des Programmes Aéronautiques, the National Aeronautics and Space Administration, and the Federal Aviation Administration.

\section{REFERENCES}

[1] HANSMAN (R.J.) and KIRBY (M.S.), Comparison of Wet and Dry Growth in Artificial and Flight Icing Conditions, J. Termophysics \& Heat Transfer, Vol. 1, № 31987.

[2] HANSMAN (R.J:),

up Analysis of Aircraft Ice Accretion, AIAA Paper 93 - 0029, Jan 1993.

[3] HOSNI (M.H.), COLEMAN (H.W.) and TAYLOR (R.P.), Measurements and Calculations of Rough-Wall Heat Transfer in the Turbulent Boundary Layer, Int. J. Heat Mass Transfer, Vol. 34, $N^{\circ} 4 / 5$, pp. 1067-1082, 1991.

[4] HEALZER (J.M.), MOFFAT (R.J.) and KAYS (W.M.), The Turbulent Boundary Layer on a Rough, Porous Plane: Experimental Heat Transfer with Uniform Blowing, Mech. Eng. Dept., Stanford University, Report HMT-18, 1974.

[5] BALAGEAS (D.L.), BOSCHER (D.M.) and DEOM (A.A.), Measurement of convective heat transfer coefficients on a wind tunnel model by passive and stimulated infrared thermography, Infrared Technology 16, SPIE Proc., Vol. 1341, pp. 339-357.

[6] HENRY (R.) and GUFFOND (D.), Infrared technique to measure skin temperature on an electrothermal de-icer, comparison with numerical simulations., AIAA Paper 89 - 0760, Jan. 1989.

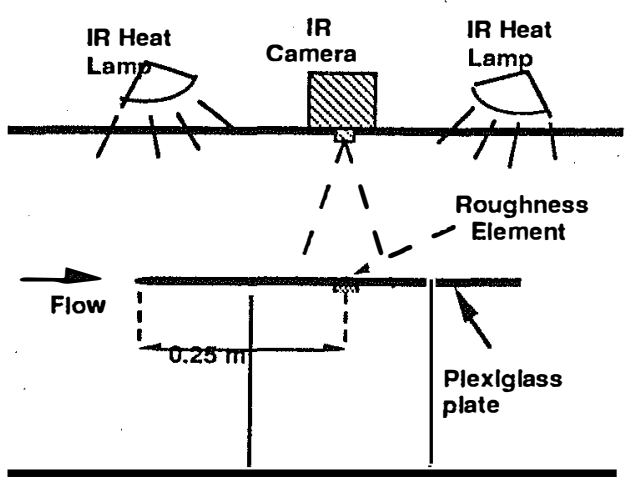

Fig 1. Schematic view of the experimental set-up.

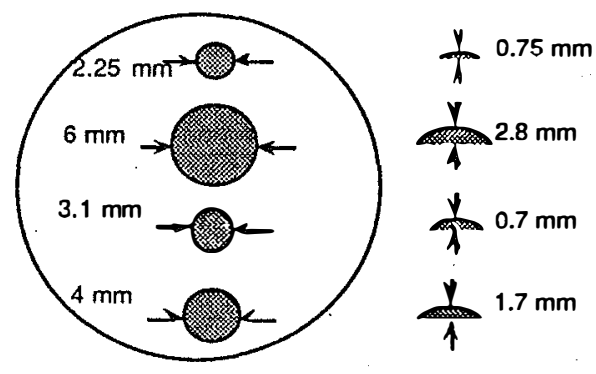

Fig. 2 Individual protuberances test configuration 


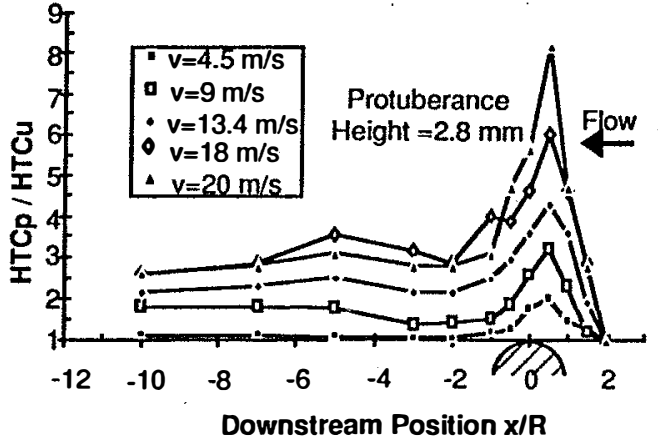

Fig. 3. Heat transier coefficient enhancement on a $2.8 \mathrm{~mm}$ high protuberance in a laminarboundary layer.

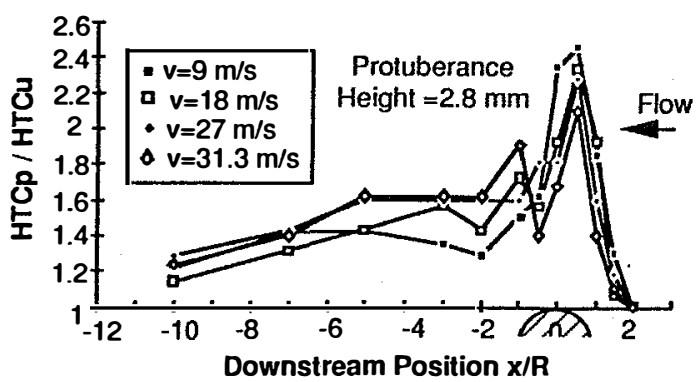

Fig. 5. Heat transfer coefficient enhancement on a $2.8 \mathrm{~mm}$ high protuberance in a turbulent boundary layer.

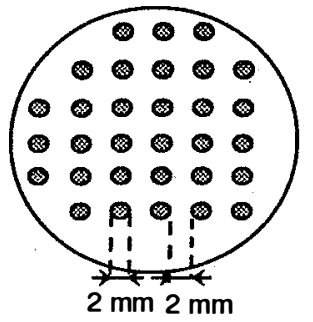

Fig. 7. Multiple protuberances test configuration.

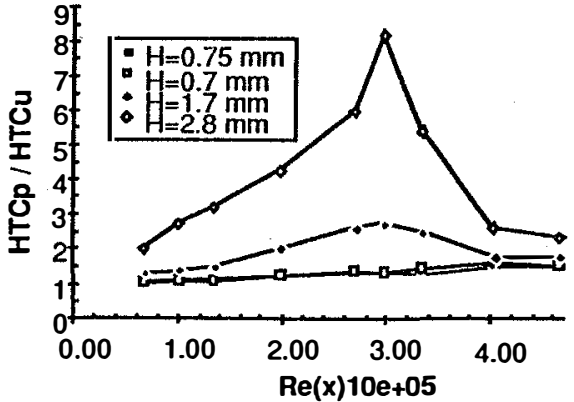

Fig. 4. Maximum heat transier coefficient enhancement in a laminar boundary layer versus Reynolds number $25 \mathrm{~cm}$ downstream of the leading edge.

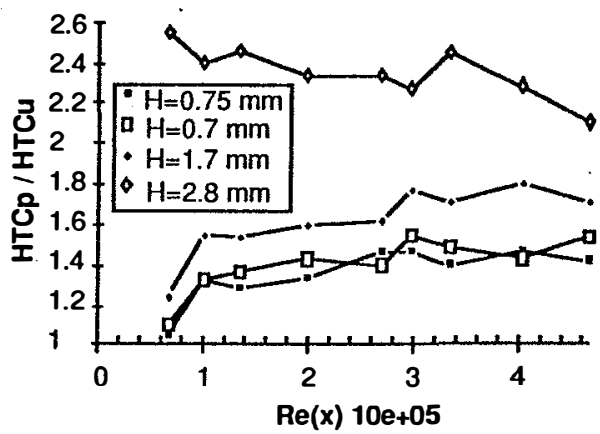

Fig. 6. Maximum heat transier coefficient enhancement in a turbulent boundary layer versus Reynolds number $25 \mathrm{~cm}$ downstream of the leading edge.

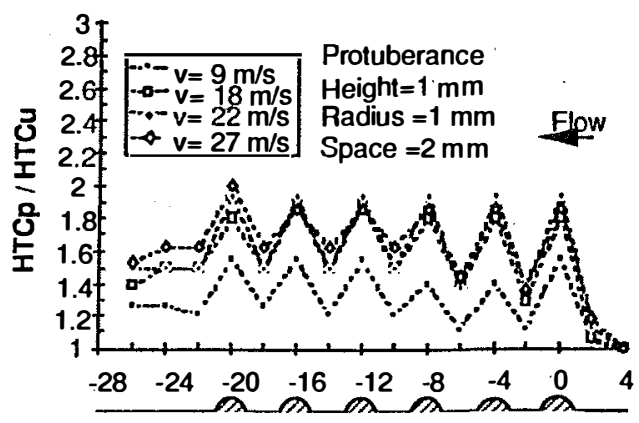

Downstream Position x/R

Fig. 8. Multiple protuberances heat transfer coefficient enhancement. 